\title{
CENTRAL EUROPEAN BLOCKING ANTICYCLONES AND THE INFLUENCES IMPRINT OVER THE ROMANIA'S CLIMATE
}

\begin{abstract}
Niță Andrei ${ }^{1}$, Apostol Liviu ${ }^{2}$
Keywords: anticyclones, Hess-Brezowsky, blocking situations, synoptic types.

Abstract Blocking anticyclonic circulations from Europe are provoking climatic episodes responsible for discomfort, human and financial loses. During the summer, these episodes are known for prolonged droughts and maximum temperatures often exceeding $35{ }^{\circ} \mathrm{C}$ to $40{ }^{\circ} \mathrm{C}$. In the cold season, the rainfalls are close to 0 while the daily minimum temperatures are low under the average period. For this study, we used a synoptic classification which is available especially for Central Europe but works similarly for Romanian territory too. We aim to follow what kind of climatic conditions these circulations are producing in Romania during their presence in Europe. ECA\&D daily gridded climatic dataset was used in this study. The study period lasts from 1961 to 2012. We used the minimum and maximum daily temperatures as well the rainfall quantities recorded. Since the output volume of data was too high, we aggregated the results into yearly multiseasonal average. In order to classify the synoptic patterns as blocking anticyclones, we used two synoptic situations from Hess-Brezowsky defined as Anticyclone High Central (HM) and High British Isles (HB). We calculated the thermic anomalies as well the rainfall quantities recorded in Romania during the presence of these circulations in central Europe. The results shows a perspective over the synoptic conditions in Romania during the presence of the above mentioned synoptic types in Central Europe.
\end{abstract}

\section{Introduction}

Blocking anticyclones are climatic episodes that are provoking discomfort through the thermic and rainfall anomalies and often damages in agricultural crops. The yearly frequency of these episodes is estimated to be about $22.7 \%$, with a persistence of 17 days for mid latitudes. The maximum reached is in April while the minimum is reached during August and September. The main characteristics for blocking consists in the Jet stream bifurcation in two branches which also

\footnotetext{
${ }^{1}$ Ph.D, stud Universitatea „Alexandru Ioan Cuza”, Iaşi, România

${ }^{2}$ Prof. Ph.D, Universitatea „Alexandru Ioan Cuza”, Iaşi, România
} 
corresponds to the weakening of the zonal flow across Europe. This happens usually near the $45{ }^{\circ} \mathrm{C}$ latitude. The transition from the zonal circulation to the meridional circulation begin in the upper levels of the troposphere. (Rex, 1950).

The drought due to the Azores Anticyclone extend to the Central Europe is specifically when the extend goes strongly towards the east and the northern continent (above France and the North Sea), regions where higher quantities of rainfalls are recorded during the year. This anticyclone has the highest frequency during the summer season, when Europe is crossed less by the Mediterranean lows as well the weakening of the Icelandic low to the North. The minimum activity is taking place during March (Oliver, 2005).

Blocking circulations are not necessarily specific for the entire European continent. During the presence of a synoptic situation above the British Isles, similarly conditions are recorded in Germany as well but not further too (as in Russia for example). This phenomena is facilitating the results which differentiates Western Europe from the eastern side as well the northern one from the southern when referring to the rainfall and temperatures distributions during the blocking episodes.

As mentioned before, during the blocking situations, there are perturbations over the westerly atmospheric flow throughout the Europe as well in the northern Atlantic. The zonal movement of air is nearly blocked which leads to a weak vorticity of air too. As an example for this kind, the drought and heat waves in Europe in 2003 were results of such an episode.

Many times during the sinuously flow of the Jet Stream, cut off levels are born. In the most situations, the blocking episodes that are specific for Scandinavia are pushing the polar lows towards the Norwegian Sea as well to south-western Europe. This pattern produces colder winters than the average in Europe (Barry and Chorley, 2003).

For the northern hemisphere, the high-over-low blocking type shows frequently on the western shore of Europe and North America, being characteristic through a divergence around the blocking center. The second blocking pattern is omega one, named since is taking the shape of the Greek letter ' $\Omega$. (Bluestein, 1993).

An analysis of blocking situations over Europe can be found in a research paper by Tyrlis and Hoskins where the authors are finding a higher frequency of blocking in the Eastern Atlantic (to Europe and Central Asia), with a secondary region in the central and eastern Pacific. As the authors proposing, the yearly frequency for blocking situations is around $24 \%$. (Tyrlis \& Hoskins, 2007)

In 1986, Benzi is proposing that a blocking episode must last longer than 10 days, with a distinct pattern for the zonal flow (Benzi et al, 1986). I. Mokhov, A. 
Timazhev și A. Lupo as well followed through climate simulations possible changes in the blocking characteristics in the northern hemisphere. Their conclusions mentioned an increasing of the general frequency of blocking episodes in the Atlantic region during the winter and summer seasons, with a more distinctive trend in $21^{\text {st }}$ century. (Mokhov, Timazhev, \& Lupo, 2014).

Rimkus, Kazys, Valiukas șu Stankunavicius used the Hess-Brezowsky synoptic classification in order to assess the drought periods in Lithuania in respect of NAO and AO phases. (Rimkus, Kazys, Valiukas, \& Stanunavicius, 2015)

\section{Methodology}

In order to classify the atmospheric circulation types, the Hess-Brezowsky classification for synoptic patterns was used. The first version was used by Paul Hess and Helmuth Brezowsky in 1952. This classification is regularly updated and by the German Institute (PIK) and P.C. Werner and W. Gerstengarbe. This classification is mainly available for central Europe, having three groups of circulation types (zonal, meridional and mixed).

For this study, two synoptic configurations were used from this classification, having their baric center over the north-western Europe and in the central European area as well. First type selected is HB (High over British Isles) which corresponds with the center of an anticyclone over the western shores of Europe together with Norwegian Sea to the North Sea). In many cases is linked with the anticyclone over the Greenland as well with the high pressure systems over Iceland. It can reach the eastern Europe during its maximum extent due to the weakening of zonal flow while the areas from the south-eastern Europe are under the cyclonic activity. (Werner \& Gerstengarbe, 2010).

The second anticyclonic situations with possible blocking implications is HM (High, Central Europe) which is defined by the presence of a high pressure system in the Central Europe. Usually, around this formation low pressure systems are met. The baric gradient is not very high. The maximum frequency is reached in September while the minimum is in April. (Werner \& Gerstengarbe, 2010). This synoptic pattern is often involved in the droughts and high temperatures during the summer season. (Kysely, 2007)

The climatic datasets used re available on the European Climate Assessment and Datasets (ECA\&D). This dataset uses a gridded database called E-OBS gridded dataset $\left(12^{\text {th }}\right.$ version) (Haylock, și alții, 2008). It contains five climatic variables (the minimum, maximum and daily temperature averages, precipitations and the sea-level pressure) that are obtained after the interpolation of the data available at meteorological posts around the Europe. The extent is covering an area between latitudes of $25^{\circ}$ South and $75^{\circ}$ North; the longitude between $40^{\circ}$ West to $75^{\circ}$ East. The resolution for this dataset is 0.25 degrees. 
In this study, we used the minimum and maximum daily temperatures as well the precipitation data. The observation period lasts from 1961 to 2012. We selected the days in which Hess-Brezowsky synoptic patterns were recorded using the data from the classification from the ECA\&D dataset. Then, we calculated thermic anomalies from the seasonal averages. For precipitation data, we calculated the percentage of rainfall recorded during Hess-Brezowky from the total seasonal average.

\section{Results HB}

During the winter season, the maximum daily temperature are lower in Romania by $0.5^{\circ} \mathrm{C}$ in the eastern side and higher in the western side of the country, where the thermic anomalies reach about $-1.9{ }^{\circ} \mathrm{C}$ comparing with the seasonal averages. On European scale, these anomalies are positive in western Scandinavia due to stationary high pressure systems in these regions and also, the transport of wet and warmer air from the ocean.

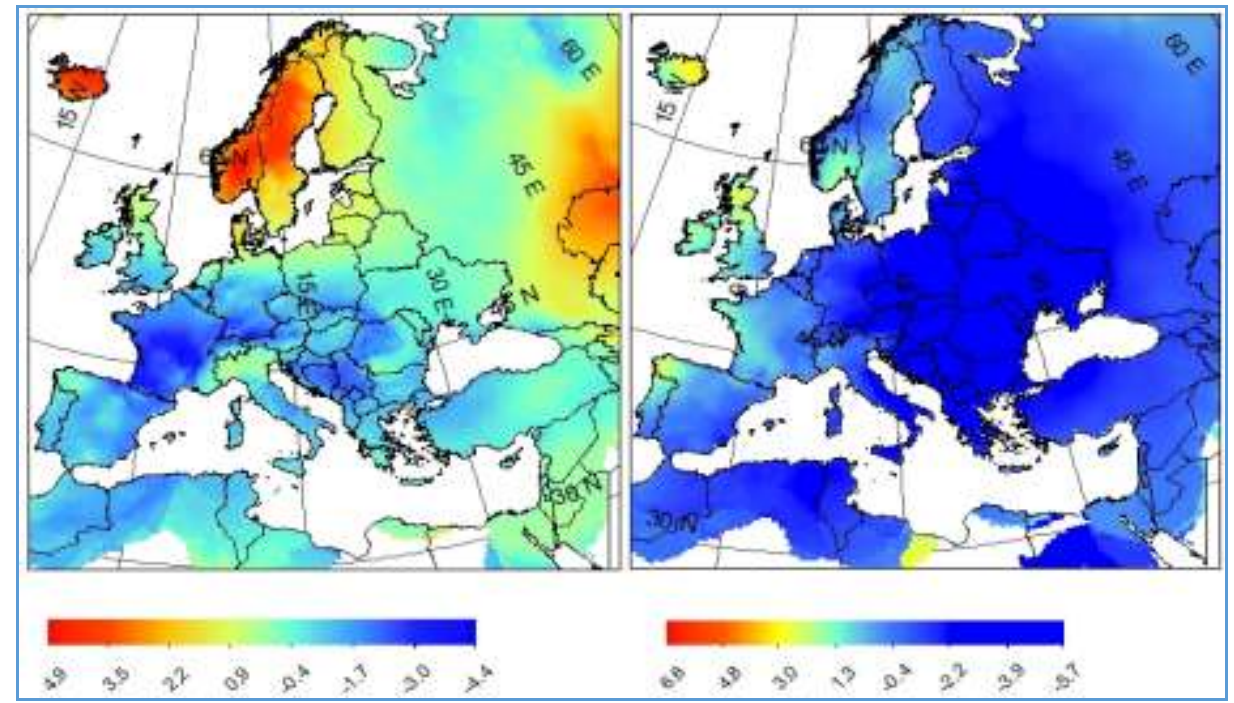

Figure 1-Maximum temperature anomalies for HB types- winter (left) and spring (right)

During the summer season, in Romania there are negative temperature anomalies compared with the seasonal averages due to the presence of low pressure systems from the southern Europe. The rest of the continent is under the presence of high pressure systems which are responsible for higher temperatures than the season averages. In Atlantic, the blocking situations are kept by the link between Azores Anticyclone and high pressure systems in the British Isles. 


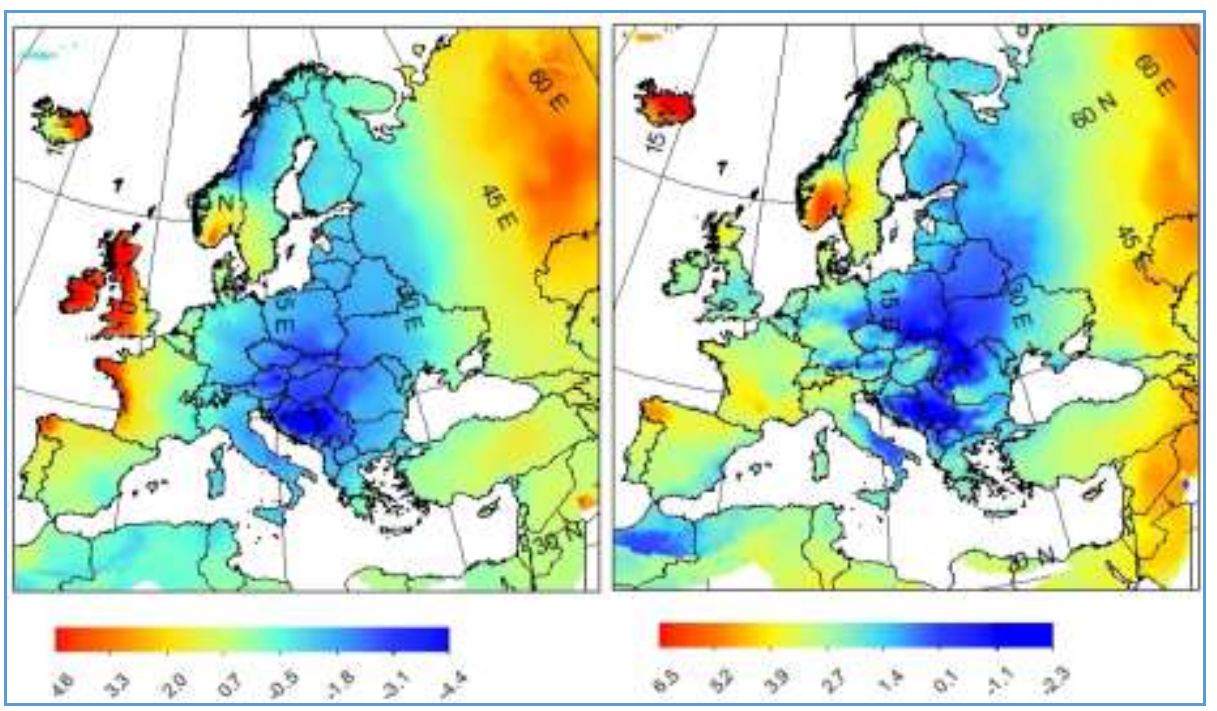

Figure 2-Maximum temperature anomalies for HB types- summer (left) and spring (right)

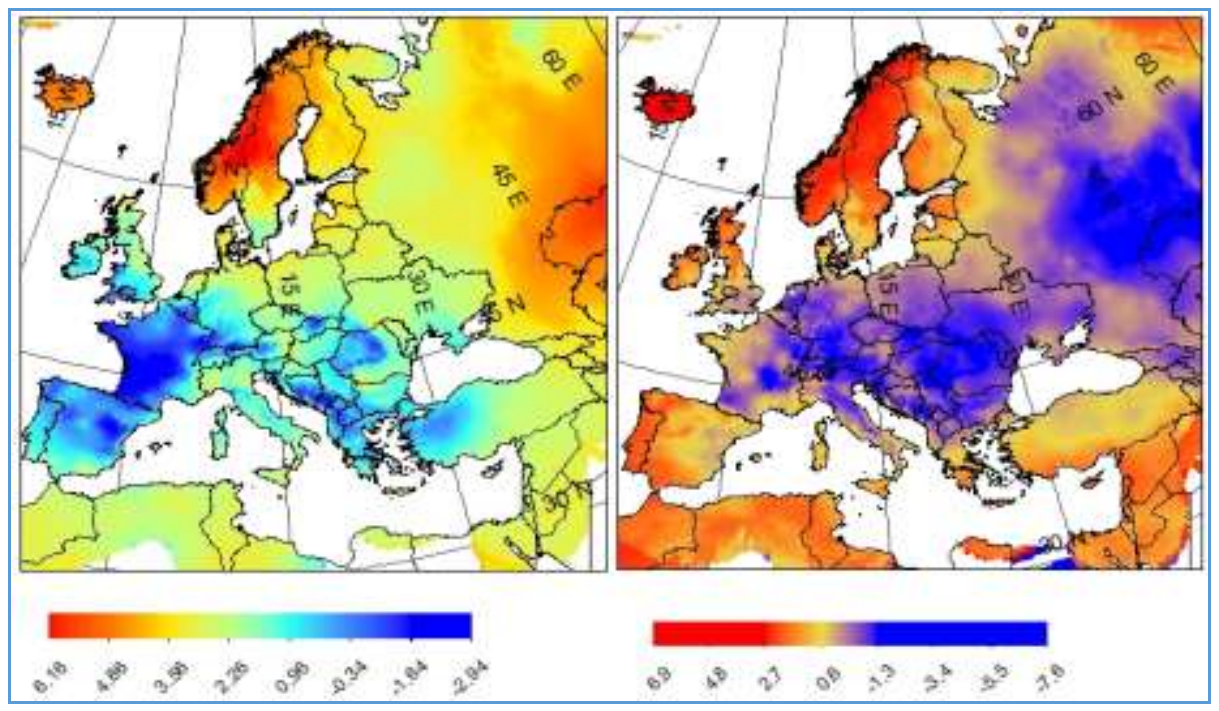

Figure 3- Minimum temperatures anomalies for HB types -winter (left) and spring right)

The minimum temperatures (fig.3 and 4) are having a similar pattern of distribution as the maximum ones. The synoptic situations specific to British Isles are lower by $0.5^{\circ} \mathrm{C}$ in Romania, with a more specific distribution in the eastern 
side (where these anomalies are lower by $-0.6{ }^{\circ} \mathrm{C}$ ) comparing with the western part of Romania where these anomalies are higher (by $-1.4{ }^{\circ} \mathrm{C}$ lower than the seasonal average). In Central Europe these anomalies are still lower. Due to the warmer and wetter air masses from the Atlantic, the temperatures during the winter season are higher in Europe.

In the summer season, these anomalies are lower too, by $-1.4^{\circ} \mathrm{C}$ in the West of Romania comparing with the season average and by $-1{ }^{\circ} \mathrm{C}$ in the eastern part. In the Western Europe, these anomalies are lower (up to $-2.0^{\circ} \mathrm{C}$ ).

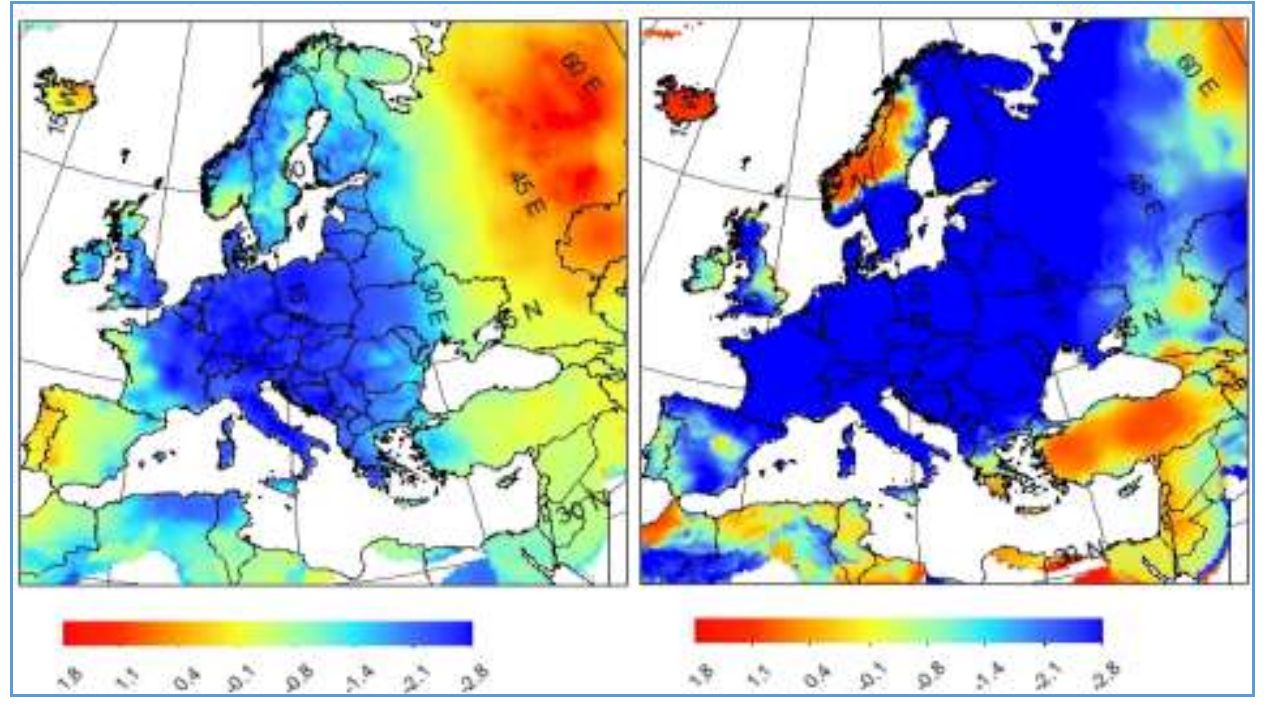

Figure 4- Minimum temperatures anomalies for HB types -summer (left) and autumn right)

The rainfall quantities are very low during the presence of blocking situations, which is also normal. During the winter season, the quantities recorded are low in central and western Europe, but higher during the spring season especially in the Eastern Europe where the presence of low pressure systems coming from the southern Europe are leading to rainfalls. (fig.5 and 6)

In the summer season, there is a net distribution between the western and eastern side of Europe where the precipitations are close to 0 in the central part of the continent and up to $30 \%$ in Romania from the seasonal totals. The same situation is similar in autumn with smaller values in Romania. 


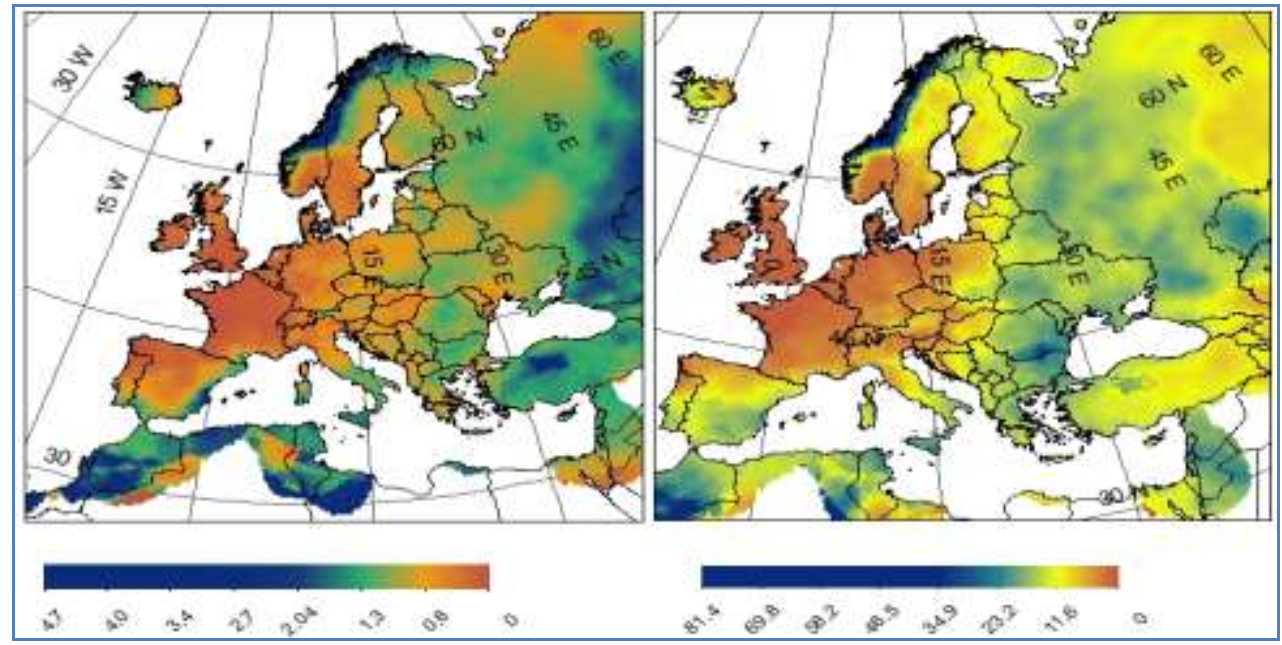

Figure 5- Percentage of rainfalls from the total seasonal average (winter and spring season).

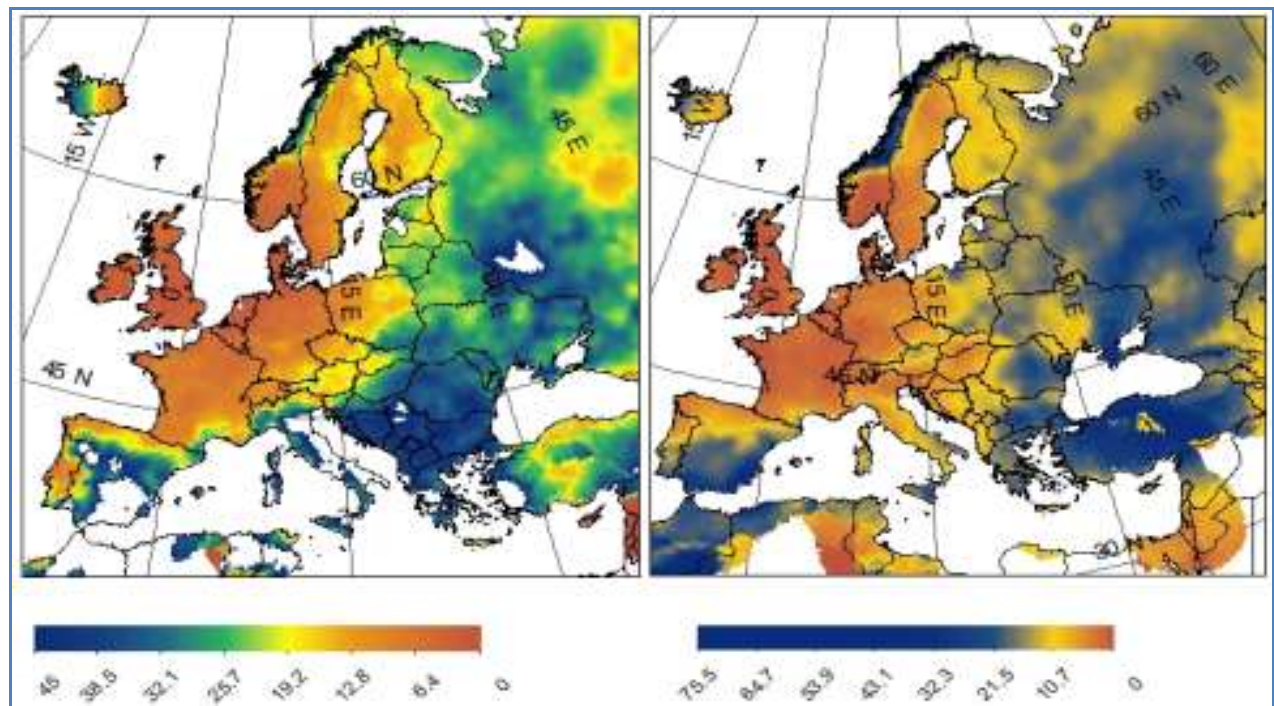

Figure 6- Percentage of rainfalls from the total seasonal average (summer and autumn season).

\section{Results HM}

The thermic anomalies for maximum temperatures are following the same trend as for the minimum ones. During the presence of high pressure systems over the central Europe, the minimum temperatures for the winter season are lower by - 
$0.5{ }^{\circ} \mathrm{C}$ than the seasonal averages in the $\mathrm{E}$ of Romania and more pronounces in the western part where they reach about -1.9 during the winter season. (fig. 6)

For the summer season, Romania has a similar trend of lower temperature comparing with the rest of the continent during the blocking circulations over the central Europe. As the blocking highs are stationed over the central Europe, the cyclonic activity and low system pressure are common at their edges. The positioning of these systems is responsible for negative anomalies in the eastern and southern part of Romania by $2.5^{\circ} \mathrm{C}$ while the temperature deviations from the Carpathian plateau are lower (by $1.7^{\circ} \mathrm{C}$ ) than the normal for this period. (fig. 7)

During the HM anticyclonic types over the Central Europe, Romania has a lower minimum temperatures than the season average. Also, the minimum temperatures are lower by $2.8{ }^{\circ} \mathrm{C}$ near the Carpathian chain (especially in the Transylvanian Plateau); the temperatures are lower in the NE and eastern Romania by $1{ }^{\circ} \mathrm{C}$. In Central Europe, these anomalies are more pronounced by having around with $3{ }^{\circ} \mathrm{C}$ less than the season's average. This is due to the radiative lose during the nights especially on the clear sky nights. While the zonal flow is stopped toward the remaining continent, the westerly circulation is felt only in Scandinavia or at the southern part of the continent. (fig. 8)

In the summer season, HM type is bringing positive anomalies in the western continent as a consequence for the high radiative volume received from Sun. The other areas from Europe are however, under the influence of cyclones which can be responsible for the atmospheric fronts that can led to higher rainfall quantities that the season's average. That's why in the rest of the continent the thermic anomalies caused are lower than the season's average. This is visible in Romania, where in the south-western part, the minimum temperatures in the summer season are lower by $2{ }^{\circ} \mathrm{C}$. (fig.9)

The rainfall quantities are not high during the HM anticyclonic residence, being close to 0 in Europe in the winter season. Some situations in the winter season are making the Mediterranean cyclones to migrate towards the north making these regions to receive higher quantities of precipitation. In Romania, about $7 \%$ from the seasonal sum is received that way. In the spring season, about $17 \%$ from the total precipitation of the season is due to these patterns in the northeast of Romania. In Europe, the same anticyclonic patterns marked by the presence of low clouds and a dusty atmosphere is relevant for these episodes. In Romania, only the eastern part of the country receives about $13 \%$ from the summer's totals. The West is getting about 9-10 \%. 


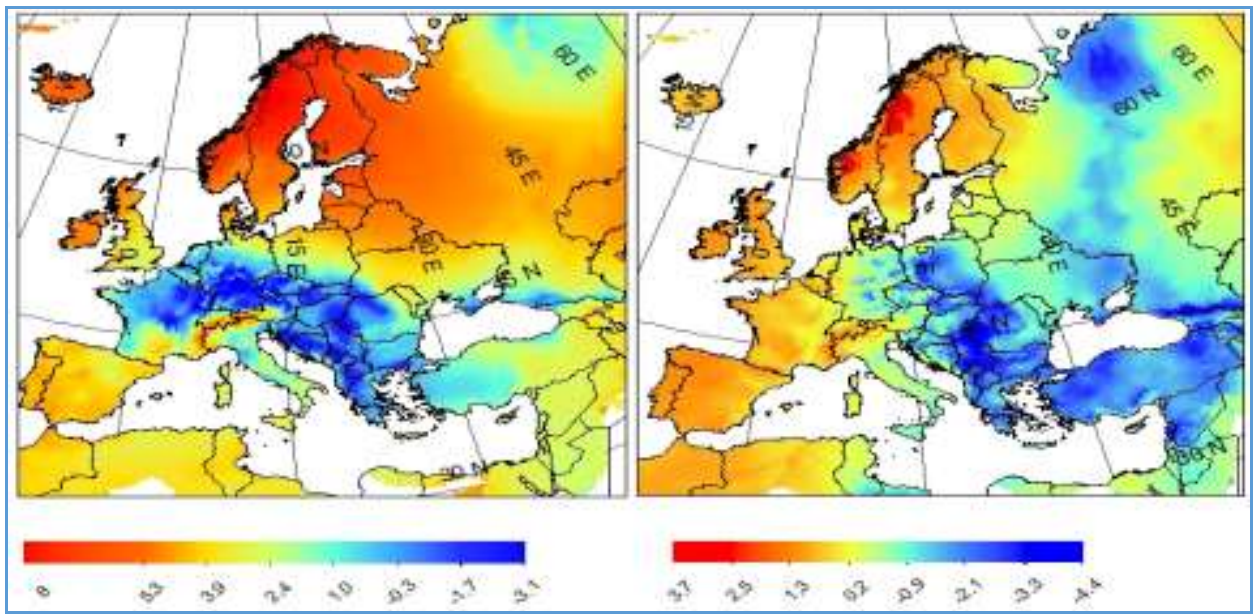

Fig. 1- Minimum temperatures anomalies for HM types -winter (left) and spring (right)

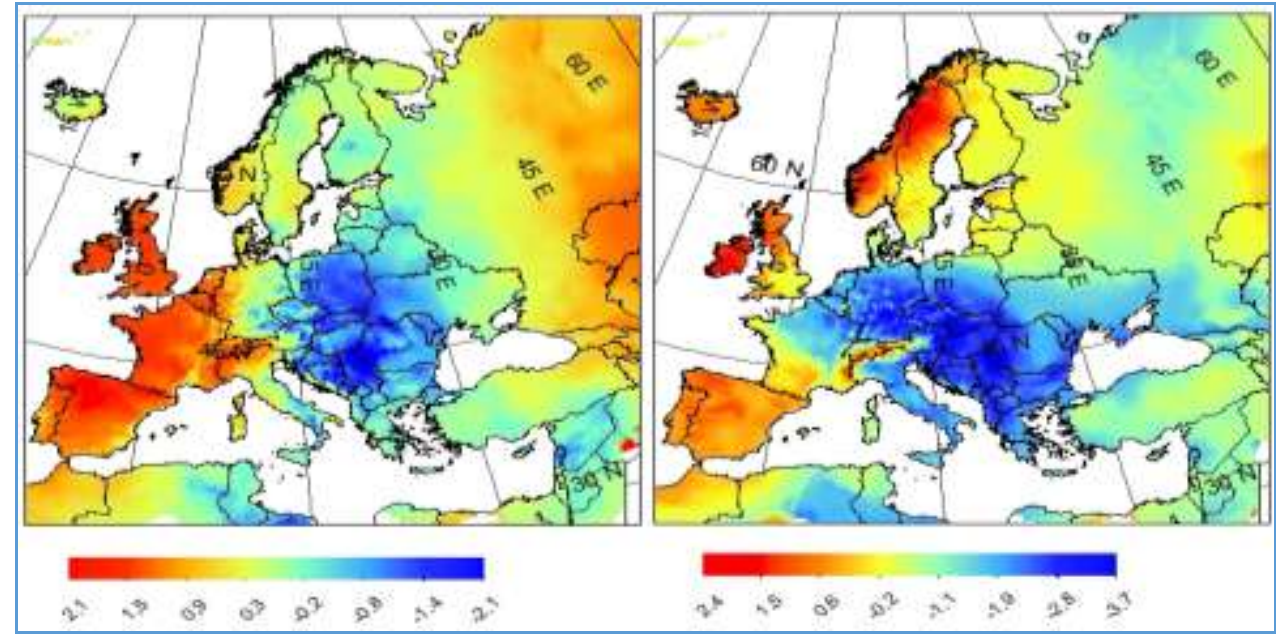

Fig. 7- Minimum temperatures anomalies for HM types -summer (left) and autumn (right) 


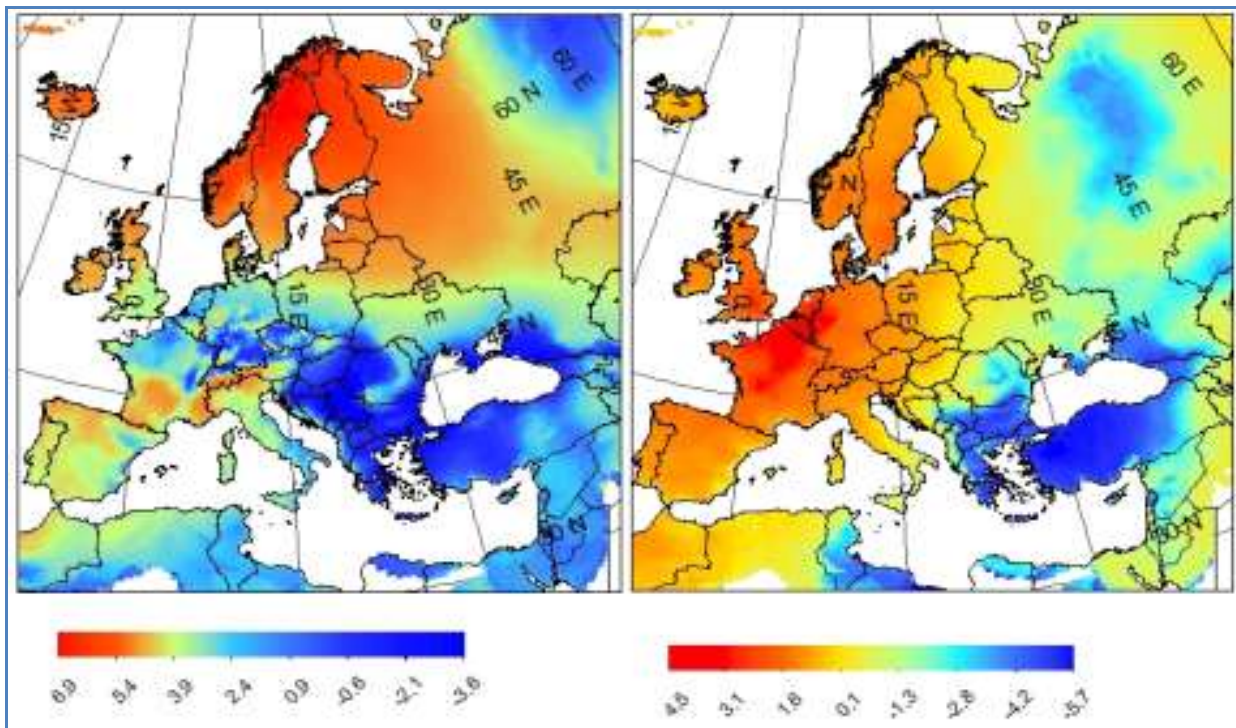

Fig. 8- Maximum temperatures anomalies for HM types - winter (left) and spring (right)

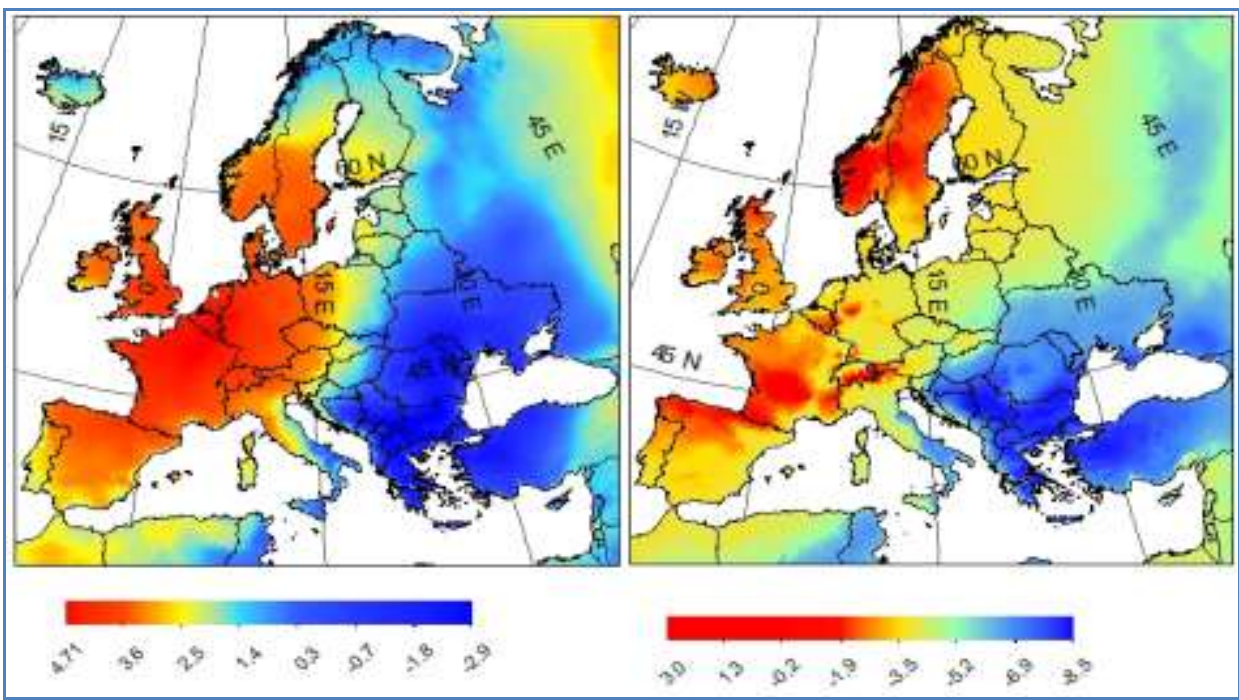

Fig. 9- Maximum temperatures anomalies for HM types -summer (left) and autumn (right) 


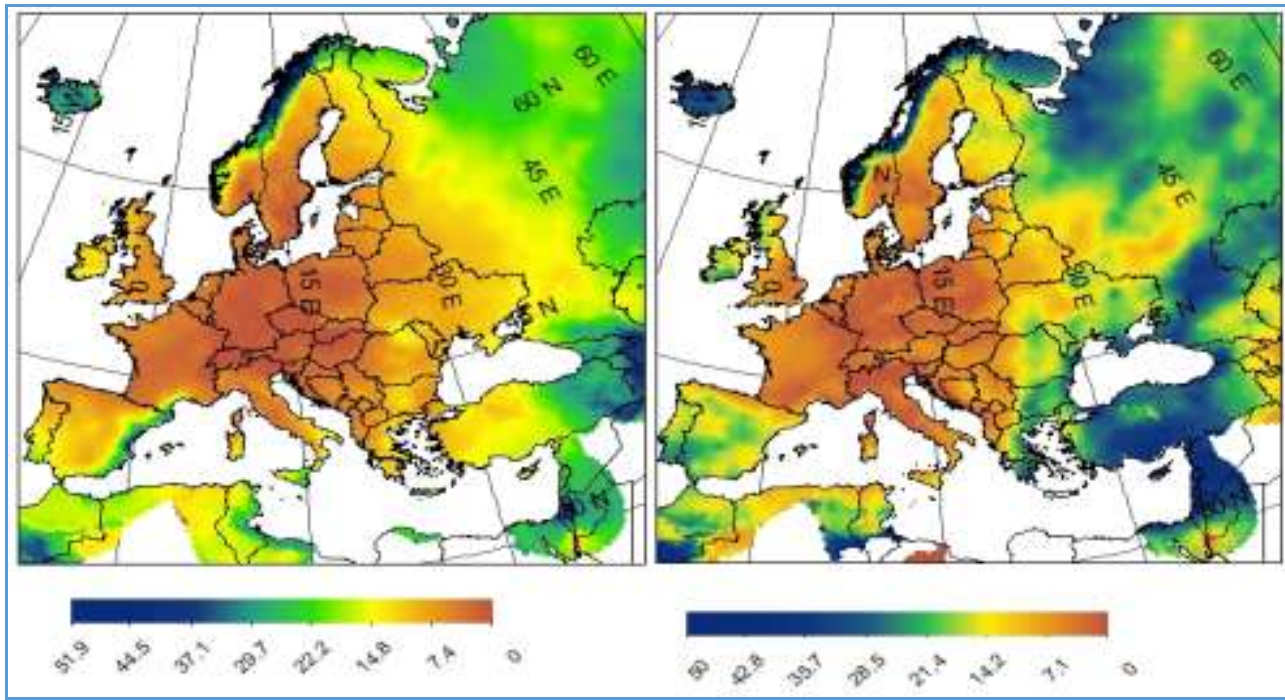

Figure 10 - Percentage of rainfalls from the total seasonal average (winter and spring season)

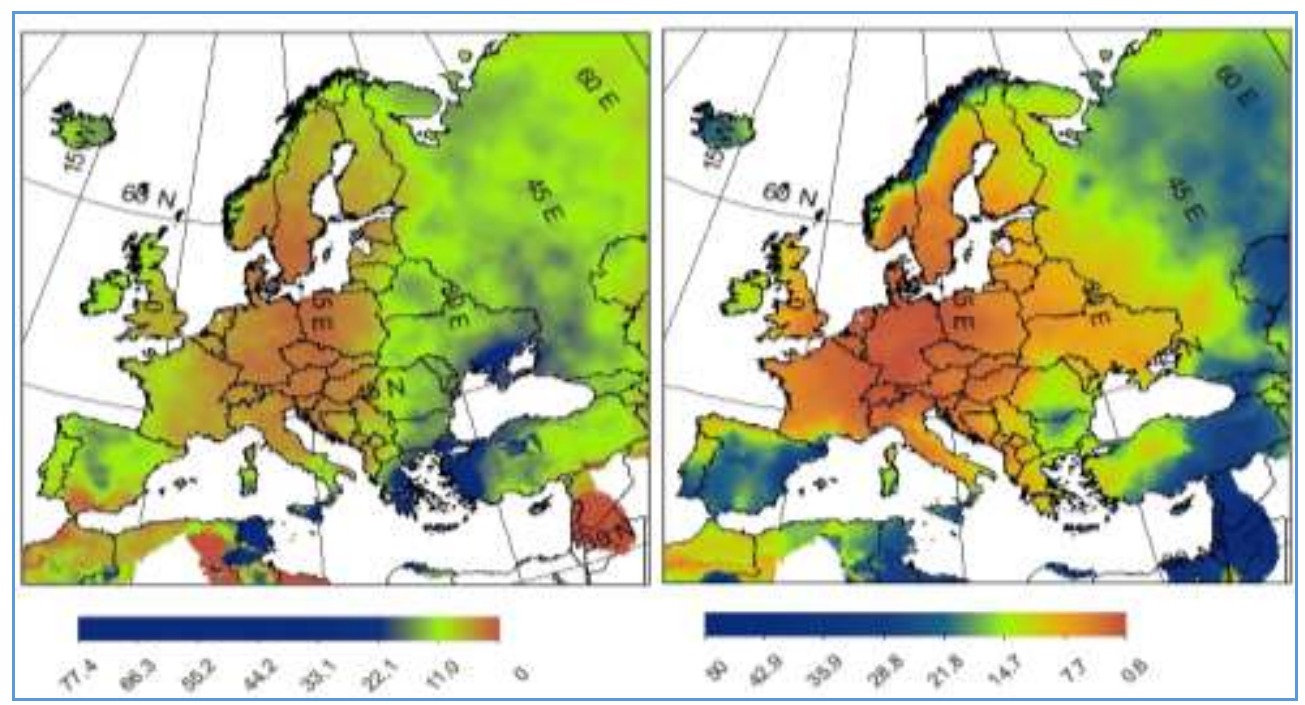

Figure 11- Percentage of rainfalls from the total seasonal average (summer and autumn season). 
The positioning of the anticyclone in the central Europe and the maximum extend of Icelandic Low towards East may provoke a lack of precipitation for Romania as well as the positioning of an anticyclonic dorsal from the northern Atlantic towards the Central Europe.

\section{Conclusions}

Synoptic situations specific to Central Europe are prevalent in Romania less than in the rest of the continent, which can be deduced from the distribution of the temperatures and rainfalls. In some situations, the results can lead to results that can be different from the climatological paradigms known. This can be relevant especially for HM types when, during the summer season, the temperatures can be lower than the season's average.

Blocking situations centered in Central Europe are responsible for a colder weather during the winter season. This situation is less relevant in Romania, but still present in the central part and western one too. For precipitation, a same situation can be seen in the Eastern Europe as well in the west.

For the spring season, there are positive anomalies for the temperatures during the blocking episodes in Central Europe. For the precipitation quantities, there is a value between 10 to $15 \%$ from the seasonal average.

During the summer season, the temperatures can be lower in Romania due to the presence of other synoptic patterns. In many cases, the blocking situations is specific only to the Central Europe and less in Romania, which is situated at the edge of this high pressure systems. This led to many invasions of polar and southern air masses carried by low pressure systems towards Romania's territory.

In the autumn season, these anomalies are negative too which shows a cooler continent. The precipitation quantities are at about $25 \%$ from the season's total for Romania, as a consequence for the presence of low pressure system and atmospheric fronts too.

\section{References}

Austin, J. (1980). The blocking of middle latitude westerly winds by planetary waves. Quarterly Journal of the Royal Meteorological Society, 327-350.

Barry, R., \& Chorley, R. (2003). Atmosphere, Weather and Climate (8th Ed.). New York: Routledge Taylor \& Francis Group.

Benzi, S. W.-N. (1986). Anomalous Atmospheric Flows and Blocking (Vol. 29). Florida, USA: Academic Press.

Bluestein,, H. (1993). Synoptic-Dynamic Meteorology in Midlatitudes. Observations and Theory of Weather Systems (Vol. 2). New York, USA: Oxford University Press. 
Haylock, M., Hofstra, N., Klok, J., Klein Tank, A., Jones, P., \& New, M. (2008). A European daily high-resolution gridded data set of surface temperature and precipitation for 1950-2006. Journal of Geophysical Research, 113-119.

Kysely, J. (2007). Implications of enhanced persistence of atmospheric circulation for the occurrence and severity of temperature extremes. International Journal of Climatology, 689-695.

Mokhov, I., Timazhev, A., \& Lupo, A. (2014). Changes in atmospheric blocking characteristics within Euro-Atlantic region and Northern Hemisphere as a whole in the 21 st century from model simulations using RCP anthropogenic scenarios. Global and Planetary Change 122, 265-270.

Oliver, J. (2005). Encyclopedia of World Climatology. Cornwall: Springer.

Rex, D. (1950). Blocking action in the middle troposphere and its effect on regional climate. The climatology of blocking actions. Tellus 2, 275-301.

Rimkus, E., Kazys, J., Valiukas, D., \& Stanunavicius, G. (2015). The atmospheric circulation patterns during dry periods in Lithuania. OCEANOLOGIA, 56 (2),, 223239.

Tyrlis, E., \& Hoskins, B. (2007). Aspects of a Northern Hemisphere Atmospheric Blocking Climatology. Journal of the atmospheric sciences, vol.65, 1638-1652.

Werner, P., \& Gerstengarbe, F. (2010). PIK Report - Katalog der Grosswetterlagen Europas (1881-2009). Potsdam, Germania: Potsdam Institute for Climate Impact Research. 
